\title{
Robust Detection of Incipient Faults in VSI-Fed Induction Motors Using Quality Control Charts
}

\author{
Luis Angel García-Escudero, Oscar Duque-Perez, Miguel Fernandez-Temprano, \\ and Daniel Morinigo-Sotelo, Member, IEEE
}

\begin{abstract}
A considerable amount of papers has been published in recent years proposing supervised classifiers to diagnose the health of a machine. The usual procedure with these classifiers is to train them using data acquired through controlled experiments, expecting them to perform well on new data, classifying correctly the condition of a motor. But, obviously, the new motor to be diagnosed cannot be the same that has been used during the training process; it may be a motor with different characteristics and fed from a completely different source. These different conditions between the training process and the testing one can deeply influence the diagnosis. To avoid these drawbacks, in this paper, a new method is proposed, which is based on robust statistical techniques applied in quality control applications. The proposed method is based on the online diagnosis of the operating motor and can detect deviations from the normal operational conditions. A robust approach has been implemented using high-breakdown statistical techniques, which can reliably detect anomalous data that often cause an unexpected overestimation of the data variability, reducing the ability of standard procedures to detect faulty conditions in earlier stages. A case study is presented to prove the validity of the proposed approach. Motors of different characteristics, fed from the power line and several different inverters, are tested. Three different fault conditions are provoked: a broken bar, a faulty bearing, and mixed eccentricity. Experimental results prove that the proposed approach can detect incipient faults.
\end{abstract}

Index Terms-Diagnostic expert systems induction motors, maintenance, monitoring, quality control.

\section{INTRODUCTION}

$\mathrm{C}$ ONDITION monitoring of induction motors is an ongoing field of research since they account for over $80 \%$ of energy conversion in industrial and commercial sectors. An ad-

Manuscript received July 1, 2016; revised September 7, 2016; accepted October 5, 2016. Date of publication October 13, 2016; date of current version May 18, 2017. Paper 2016-IDC-0469.R1, approved for publication in the IEEE TRANSACTIONS ON INDUSTRY APPLICATIONS by the Industrial Drives Committee of the IEEE Industry Applications Society. This work was supported in part by the Spanish "Ministerio de Economía y Competitividad" (MINECO) and FEDER program in the framework of the "Proyectos I+D del Subprograma de Generación de Conocimiento, Programa Estatal de Fomento de la Investigación Científica y Técnica de Excelencia (DPI2014-52842-P, MTM2015-71217-R, and MTM2014-56235-C2-1-P)" and in part by Consejería de Educación de la Junta de Castilla y León under Grant VA212U13.

L. A. García-Escudero and M. Fernandez-Temprano are with the Department of Statistics and Operational Research at E.I.I., University of Valladolid, Valladolid 47011, Spain (e-mail: lagarcia@eio.uva.es; miguelaf@eio.uva.es).

O. Duque-Perez and D. Morinigo-Sotelo are with the Department of Electrical Engineering at E.I.I., University of Valladolid, Valladolid 47011, Spain (e-mail: oscar.duque@eii.uva.es; daniel.morinigo@eii.uva.es).

Color versions of one or more of the figures in this paper are available online at http://ieeexplore.iee.org.

Digital Object Identifier 10.1109/TIA.2016.2617300 equate warning of incipient faults via condition monitoring has important advantages such as prevention of costly shutdowns, providing sufficient time for controlled shutdown of the process, reducing the costs of outage time and repairs, diagnosing present maintenance needs, scheduling future preventive maintenance, and providing safer operation of the motors Therefore, the availability of a method capable of detecting incipient faults is of great interest.

Moreover, nowadays, there is a great amount of motors that are fed by voltage source inverters (VSI). Consequently, a practical condition monitoring scheme must have the ability to detect a faulty machine independently of the power source. Nevertheless, as it has been widely reported, detection and diagnosis are more challenging for VSI-fed motors due to the rise in noise, dynamically changing excitation frequency [1]-[3], and the fact that the field harmonics amplitude is affected by the supply voltage, particularly when speed control is based on voltage regulation, keeping constant the voltage/frequency ratio [4], and that harmonic content depends strongly on the used technique for the control of the inverter and the chosen switching frequencies [5].

One of the most active fields in this area is the application of machine learning techniques to the automatic detection of faulty motors with the aim of improving the reliability and efficiency of the diagnosis. A considerable amount of papers have been published in recent years proposing supervised classifiers to diagnose the health of the machine. These classifiers provide a function (linear or nonlinear depending on the chosen classifier) to separate the data into two or more classes. This function is inferred from a set of training examples characterized as a labeled training data, with the labels corresponding to the different motor conditions to diagnose.

One of the most popular tools in diagnosis is the artificial neural networks. They have been extensively used to monitor broken bars [6]-[11], eccentricity [12]-[14], and bearingrelated faults [7]-[10], [15]-[21]. Similarly, the use of support vector machines to diagnose motors faults has been widely reported in literature: for broken bars [6], [22]-[25], bearings [19], [26]-[33], and eccentricity [29].

Other machine learning tools have also been reported in literature. $K$-nearest neighbors has been applied to diagnose broken bars [6] and bearing faults [34]. Farajzadeh-Zanjani et al. [35] use a supervised fuzzy-neighborhood density-based clustering to diagnose bearing faults. Peng and Chiang [36] apply random forest algorithm and $\mathrm{C} 4.5$ decision tree to ball bearing fault di- 
agnosis. In [37], bagging, boosting, and stacking methods are implemented to classify eccentricity, broken bars, and bearings faults via simulation. In [38], broken bars and bearings faults are diagnosed with a common vector approach. A hidden Markov model is applied in [39] to diagnose broken bars and in [40] to bearing faults too, and in [41], the hidden Markov model is combined with a Naïve Bayesian modeling. Decision trees are used in [38] and [42] to bearing faults, and in [43], decision trees are combined with Fuzzy Min-Max (FMM) neural networks, comprising a hybrid intelligent model to diagnose eccentricity.

Some applications of unsupervised learning techniques to diagnose bearing-related faults have also been reported. In these cases, the data are unlabeled and the procedure tries to find hidden structure from the data. In [44], a $K$-means clustering approach is proposed, while in [45] a weighted local and global regressive mapping algorithm is proposed and compared with other unsupervised learning algorithms, such as locality preserving projection, Isomap, principal component analysis, and Sammon mapping.

The aforementioned methods are attractive although they require an initial training phase that is critical for optimal operation. The training phase requires a large set of examples and may be misleading or produce results limited to a set of systems [46]. The usual procedure with these classifiers is to train them using data acquired through controlled experiments. The motor is run in its healthy state and then is taken to a faulty condition (or several intermediate conditions). Once the classifier has been trained with these data, it is expected to perform well on new data and then to correctly classify the condition of a motor. But, obviously, the new motor to be diagnosed cannot be the same that has been used during the training process; it may be a motor with different characteristics and fed from a completely different source. These different conditions between the training process and the testing one can deeply influence the diagnosis.

To avoid these drawbacks, in this paper, a new method is proposed, which is based on statistical techniques applied in quality control applications. The proposed method is based on the online diagnosis of the operating motor, and it can detect deviations from the normal operational conditions.

Throughout continuous monitoring of the motor, data can be acquired that correspond to abnormal conditions that do not reflect a faulty condition but other situations such as measurement or acquisition errors. These anomalous data often cause an unexpected overestimation of the data variability. As a consequence, this overestimation reduces the ability of standard (nonrobust) procedure to detect faulty conditions in earlier stages. To avoid it, a robust approach has been implemented using highbreakdown statistical techniques, which can reliably detect outliers in the data. Another interesting approach is given in [47] where a quick adaptation mechanism is proposed in the online multivariate monitoring process aimed at dealing with operating changes (for instance, intentional operators commands). On the other hand, our proposed methodology aims at dealing with nonintentional and occasional changes in data, for instance, due to bad measurements or data acquisition problems. In fact, our main contribution in this paper is the proposal of using robust (high breakdown point) techniques as a tool for a better detection of incipient faults in VSI-fed induction motors. This method- ology has not been previously considered in the literature for this problem.

The proposed technique uses a multiresolution technique based on wavelet functions to smooth the background noise in the spectrum to enhance the detection of significant fault signatures, and then, a quality control approach based on robust multivariate control charts using Hotelling's $T$-square test is applied to detect a progressive deterioration of the motor condition.

The fault signatures use to diagnose induction motors is explained in Section II, while in Sections III and IV, the statistical technique proposed is exposed and applied to a case study in Section V.

\section{FAULT SignaturES}

The proposed methodology to diagnose faulty induction motors can take advantage of any fault signature among all that have been proposed in bibliography. Hence, it can be used in any motor running condition, in stationary or nonstationary regime, as long as a measurable quantity can be extracted. Moreover, the signatures can be extracted from any physical signal acquired from the running motor, that is, stator current, vibration signal, axial flux, torque, etc., in frequency domain, time domain, or time-frequency domain [48]. The signatures can be mixed independently of the regime or signal where they have been extracted.

There is only one practical limitation on the number of signatures to be used. This limitation is related to the calculation of the covariance matrix of the signatures, and it is inherently related to the number of tests that have been performed on the motor. The greater the number of tests, the greater the number of features that can be selected. Nevertheless, the use of features that do not contribute to explain the variability of the response variable (the motor condition) can disturb the performance of the diagnosis procedure. Hence, a feature selection can be advisable using any available procedure. ANOVA [49] or a dimension reduction technique such as principal component analysis [50] can be used to estimate the variability of the response explained by the feature

In the case study analyzed in Section V, stator current is the signal measured and processed, which is a common practice in this field, due, mainly, to the advantages that it provides the used sensor (a clamp meter), being noninvasive, cheap, and easy to manage. The features are extracted in the frequency domain using fast Fourier transform (FFT) to analyze the stator current during a steady-state operation of the motor.

In these conditions, the characteristic fault frequencies are well known. In the case study shown in Section $\mathrm{V}$, three different faults are analyzed: broken bars, mixed eccentricity, and bearing faults.

When the motor is supplied by a solid-state inverter, line current will contain time harmonics, which will modify the amplitude of existing harmonics or will generate new air gap spatial ones. Therefore, in the case of cage asymmetry and nonsinusoidal voltage supply, fault signatures are identified as sidebands around the frequencies of time harmonics of line current, at frequencies given by

$$
f_{\mathrm{bb}}=(k \pm 2 n s) f_{1}
$$


where $k$ is the order of the line current time harmonics, $s$ is the motor slip, $f_{1}$ is the main frequency, and $n$ is any positive integer.

In the case of a bearing-related fault, since ball bearings support the rotor, any bearing defect will produce a radial motion between the rotor and stator of the machine, causing the machine air gap to vary in a manner that can be described by a combination of rotating eccentricities moving in both directions [51]. Therefore, a faulty bearing can be diagnosed observing the sidebands around the stator current harmonics due to the frequency power converter at frequencies given by

$$
f_{\text {brn }}=\left[k \pm n q \frac{(1-s)}{p}\right] f_{1}
$$

where $p$ is the number of pair of poles and $q$ depends on the kind of bearing fault and on the characteristics on the bearing (number of balls, ball diameter, and ball pitch diameter, respectively, and the contact angle of the ball with the races) [52].

For mixed eccentricity, in VSI-fed motors, the fault frequencies are observed as sideband pairs around principal current harmonics introduced by the power supply, situated at a distance equal to the mechanical rotation frequency, according to (3)

$$
f_{\text {ecc }}=k f_{1} \pm n f_{r} .
$$

where

$$
f_{r}=\left[\frac{1-s}{p}\right] f_{1} .
$$

\section{QUALITY CONTROL CHARTS}

Control chart is surely the most widely used tool of the "magnificent seven" tools [53] of Statistical Process Control (SPC). In the recent literature of SPC, it is common to distinguish two phases in the development and implementation of control charts. Phase I, sometimes called Initial Study (e.g., see [54]), is primarily used, according to [53], to bring the process to a state of statistical control, analyzing historical process data to establish an initial set of in-control data that contains no outliers [55]. This analysis may require several iterations to detect these points and correct its causes. In the multivariate context we are considering, the construction of this initial in-control data set is more difficult as some additional problems not arising in the univariate context may appear such as, among others, the determination of the proper functional form of the variables involved, the possible appearance of multicollinearity, which would lead to an unstable estimate of the covariance matrix of the variables and the determination of multivariate outliers. A full description of these problems and the ways of dealing with them can be found in [56].

Once the in-control data set has been established, the in-control process parameters estimated and the control limits determined, in Phase II, also called Control to Standard, the process is monitored comparing the successive observed values of the process with the control limits thus detecting when the process goes out of control. In the multivariate context, the interpretation of out-of-control signals is also more involved than in the univariate case as the reason for this signal may come, for example, from one or more of the variables considered or from departures from the correlation structure coming from the in-control data set. Several methods have been developed to interpret out-of-control signals such as the MYT decomposition [57] or Hawkings method based on regression adjustments [58]. A comparative study of these classical methods can be found in [59]. More recently, classification techniques, such as, among others, neural networks or decision trees, are being used to analyze and interpret these signals. In [60]-[62], a description of these methods is given, together with a comparison among them, with boosting [63] showing the best performance according to [62].

\section{Robust Quality CONTROL CHARTS}

As previously commented, two phases may be distinguished in quality control charts.

Phase I: Assume that $x_{i}=\left(x_{i 1}, \ldots, x_{\mathrm{ip}}\right)^{\prime}, i=1, \ldots, n$ are the $n$ observations taken from the in-control situation after measuring key $p$ features (e.g., $p$ seemingly important features extracted from the frequency domain). It is quite common to use the Hotelling's T2 chart as a quality control tool. This chart is based on monitoring the squared Mahalanobis distance, which measures the distance of $x_{i}$ to the overall sample mean vector $\bar{x}$ and takes into account the covariance structure through the sample covariance matrix $S$. In other words, this Hotelling's T2 chart is based on the monitoring of

$$
T_{i}^{2}=\left(x_{i}-\bar{x}\right)^{\prime} S^{-1}\left(x_{i}-\bar{x}\right), \quad i=1, \ldots, n .
$$

When monitoring these quantities, the following upper control limit (UCL) is often applied:

$$
\mathrm{UCL}=\frac{(n-1)^{2}}{n} B_{\alpha ; \frac{p}{2}, \frac{n-p-1}{2}}
$$

where $B_{\alpha ; u, v}$ is the $(1-\alpha)$ percentile of the beta distribution with parameters $u$ and $v$. The use of these limits guarantees a probability $\alpha$ of false alarm for each observation when assuming multivariate normality for the observations.

However, it is also well known that the sample mean $\bar{x}$ and the sample covariance matrix $S$ can be heavily influenced even by a small amount of outlying observations. Unfortunately, unexpected outliers are likely to appear in our in-control sample of observations, given the high signal-to-noise ratios frequently present in the spectrum, which may result in occasional problems in the determination of their monitored peaks. Moreover, multiple outliers tend to inflate the classical variance-covariance estimates in such a way that they can "mask" each other. This problem is often known as "masking effect" [63]. The overestimation of the scatter of the in-control data causes that all the $T_{i}^{2}$ in (5) simultaneously shrink. Therefore, it may be wrongly decided to use all the observations to estimate the in-control parameters. Consequently, there will be problems in Phase II for detecting out-of-control cases.

To overcome this trouble with outlying observations, it was suggested to replace the sample mean and the sample covariance matrix $S$ by robust location and scatter matrix estimates [64]-[66]. For instance, the minimum covariance determinant 
Tolerance ellipse $\mathbf{( 9 7 . 5 \% )}$

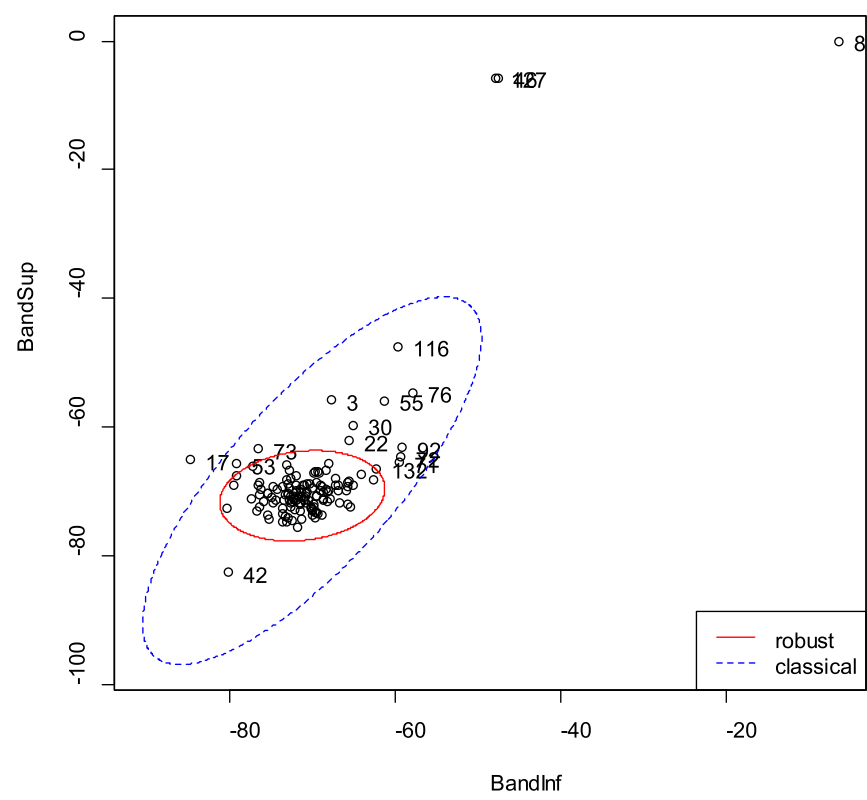

Fig. 1. Tolerance ellipses for the first sideband around the main harmonic acquired from the healthy motor. Motor fed from an AB VSI.

(MCD) and the minimum volume ellipsoid (MVE) estimators [65] can be used.

Focusing on the MCD as high-breakdown procedure, this estimator can be applied by resorting to covMcd function within the robustbase package available at the CRAN repository (http://www.cran.r-project.org) This package returns robust location and scatter matrix estimators denoted, respectively, as $\overline{x_{\mathrm{MCD}}}$ and $S_{\mathrm{MCD}}$.

Using these estimators, the robustified Hotelling's T2 distances can be defined as

$$
\begin{aligned}
T_{i, \mathrm{MCD}}^{2} & =\left(x_{i}-\overline{x_{\mathrm{MCD}}}\right)^{\prime} S_{\mathrm{MCD}}^{-1}\left(x_{i}-\overline{x_{\mathrm{MCD}}}\right), \\
i & =1, \ldots, n .
\end{aligned}
$$

The distribution of this robustified $T^{2}$ statistics does not admit a closed explicit form, but, in order to establish UCL, simulations can be used [65].

Fig. 1 shows how traditional Mahalanobis distances are inflated due to the presence of a few outlying observations and, thus, the classical tolerance ellipsoids (i.e., the use of traditional Mahalanobis distances) can fail at detecting other clearly anomalous observations. For instance, traditional (nonrobust) Hotelling's T2 chart can detect the three most clear outliers in the "Broken bar diagnosis" example in the following section. However, this method fails at detecting other outlying observations that remain hidden due to the "masking" effect. On the other hand, we can detect these three clear outlying observations together with many other outlying ones (see Fig. 2 top) when using the robustified $T^{2}$ statistics and a robust Hotelling's T2 chart.

Therefore, the proposal for Phase I is trying to remove as much as possible outlying observations. With this idea in mind,
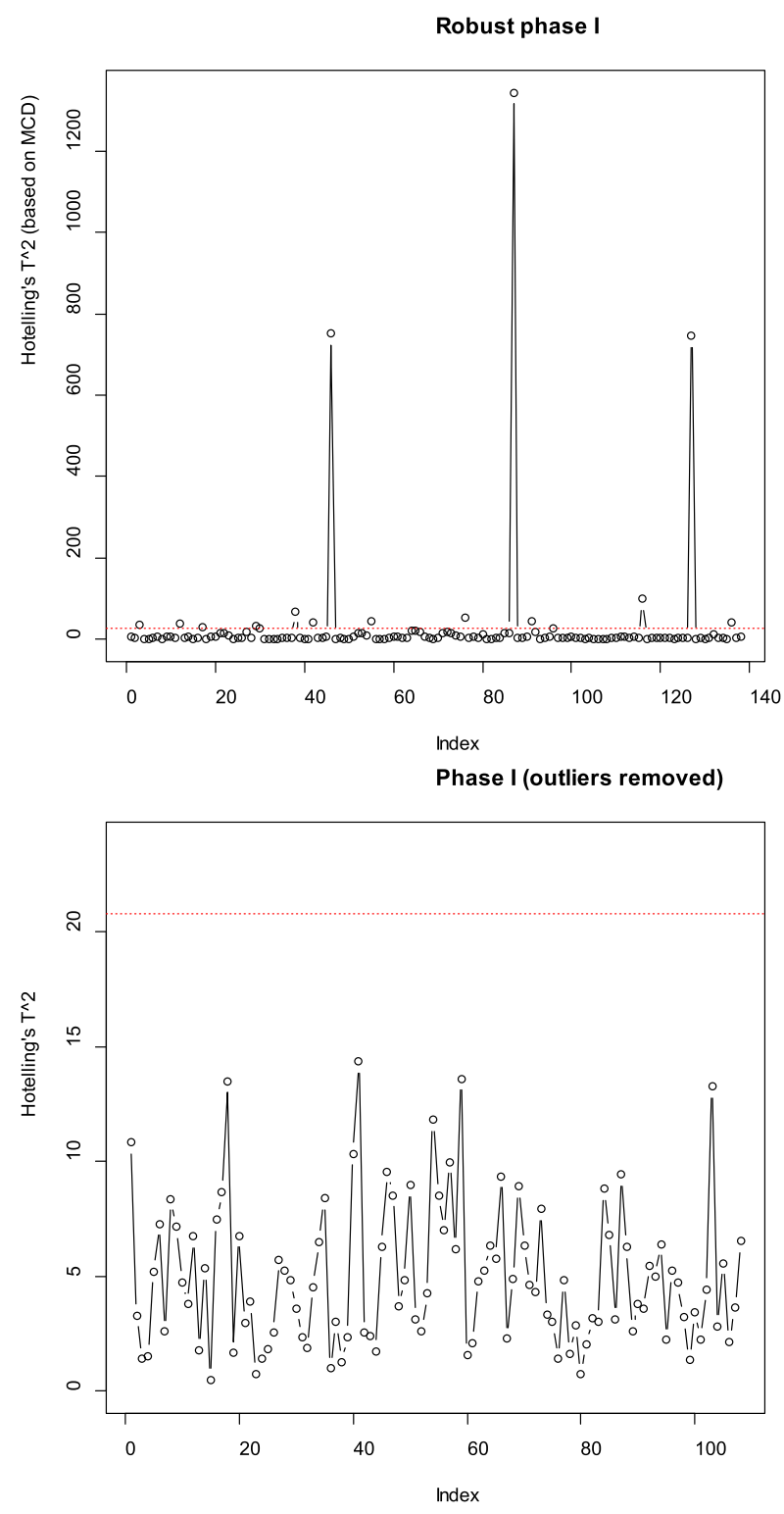

Fig. 2. Robust Phase I charts with outliers (top) and with outliers removed (bottom). The horizontal line marks the quality control warning. When the outliers have been removed all the tests are in-control. Motor fed from an $\mathrm{AB}$ VSI.

the $x_{i}$ observations satisfying

$$
T_{i, \mathrm{MCD}}^{2}>\chi_{0.025 ; p}^{2}
$$

are going to be directly discarded from the in-control sample. $\chi_{\alpha ; p}^{2}$ stands for the $(1-\alpha)$ percentile of the chi-squared distribution with $p$ degrees of freedom. Note that covMcd function in the robustbase package already incorporates a consistency factor and a finite sample correction factor to achieve consistency under the multivariate normal assumption [67].

Phase II: By using the criteria in (8), a subset of indexes $\left\{i_{1}, \ldots, i_{m}\right\} \subset\{1,2, \ldots, n\}$ is obtained for a subsample of (hopefully) outlier-free data points to be considered as in-control data. Then, the sample mean $\overline{x_{-o u t}}$ and the sample covariance matrix $S_{- \text {out }}$ of this subset made up with $m$ observations are computed. A "robust phase II" chart is then 
TABLE I

SPECIFICATIONS OF THE TESTED MOTORS

\begin{tabular}{lccccc}
\hline \hline Motor & $\begin{array}{c}\text { Rated Power } \\
(\mathrm{kW})\end{array}$ & $\begin{array}{c}\text { Rated Voltage } \\
(\mathrm{V})\end{array}$ & $\begin{array}{c}\text { Rated Current } \\
(\mathrm{A})\end{array}$ & $\begin{array}{c}\text { Rated Speed } \\
(\mathrm{r} / \mathrm{min})\end{array}$ & Pole Pairs \\
\hline M1 & 0.75 & $3 \times 230 / 400$ & 1.9 & 1395 & 2 \\
M2 & 1.1 & $3 \times 230 / 400$ & 2.6 & 1415 & 2 \\
\hline \hline
\end{tabular}

TABLE II

Description of the Tests PERFORMEd (BROKEN BAR CONDITION)

\begin{tabular}{lcc}
\hline \hline Condition State & Description & Hole Depth $(\mathrm{mm})$ \\
\hline 1 & Healthy motor & 0 \\
2 & Incipient fault & 6.4 \\
3 & Semi-broken bar & 11.7 \\
4 & Full-broken bar & 17 \\
\hline \hline
\end{tabular}

derived by examining

$$
T_{i, \text { out }}^{2}=\left(x_{i}-\overline{x_{- \text {out }}}\right)^{\prime} S_{- \text {out }}^{-1}\left(x_{i}-\overline{x_{- \text {out }}}\right)
$$

where $x_{i}$ are the new observations to be monitored. The UCL is also changed to

$$
\mathrm{UCL}_{m}=\frac{(m-1)^{2}}{m} B_{\alpha ; \frac{p}{2}, \frac{m-p-1}{2}}
$$

i.e., as in (6) but now only based on those $m$ outlier-free subsample.

An observation is finally labeled as out of control if $T_{i,- \text { out }}^{2}>$ $\mathrm{UCL}_{m}$. In the next section, the proportion of observations labeled as out of control when using this approach is compared to the traditional "nonrobust phase II." Distances (5) and the cut-off value (6) are directly applied in "nonrobust phase II."

\section{CASE STUdy}

Several controlled laboratory experiments were carried out on induction motors of two kinds of specifications, as shown in Table I. The motors were fed from different sources, utility supply (UT), and VSIs by different manufacturers. Both motors were loaded with a magnetic powder brake. The following instrumentation and software was used to collect and analyze data: a Fluke Hall Effect probe, a PCI-6250 M DAQ board by National Instruments, LabView, MATLAB, and R statistical software. The data acquisition resolution was $80 \mathrm{kHz}$. MATLAB was used to process the motor line current estimating the power spectral density (PSD) from the signal applying the Hanning Window in order to reduce the spectral leakage. In order to obtain a normalized PSD, the function provided by MATLAB has been modified, with the amplitude of the fundamental frequency corresponding always to $0 \mathrm{~dB}$.

\section{A. Broken Bar Diagnosis}

Four rotor conditions (see Table II) were tested by progressively drilling a hole into one of the rotor bars. The motor was fed from three different sources: utility supply and two VSIs by Allen Bradley $(\mathrm{AB})$ and Siemens and at different operating
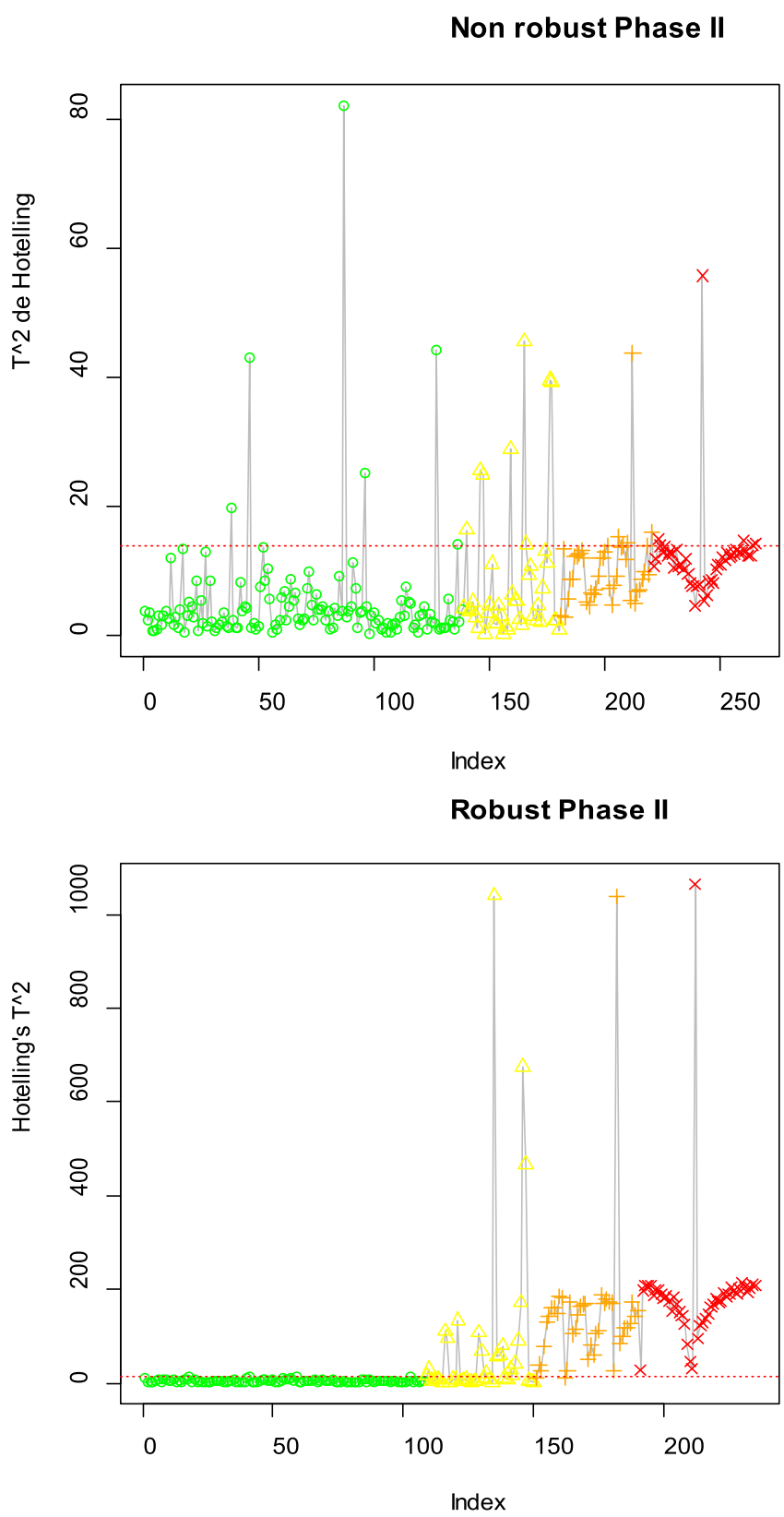

Fig. 3. Phase II charts. Nonrobust (top) and robust (right) approaches. The dots are the healthy motor tests (100 tests). The triangles, crosses, and x symbols represent the different faulty (broken bar) condition states (see Table I) (50 tests for each condition). Motor fed from an AB VSI.

frequencies $(35,50$, and $65 \mathrm{~Hz})$. As fault signatures, the first sideband around the main harmonic was used. Nevertheless, as it has been stated in Section I, the proposed method does not limit the number or the characteristics of the features used. In cases where the detection might be especially challenging, more features can be used, extracted from current signal or from other signals (such as vibration acoustic or axial flux signals, for example).

To thoroughly describe the proposed methodology, one of the tested cases is now explained in detail. In this case, a motor of type $\mathrm{M} 2$ is fed from a VSI by $\mathrm{AB}$ with an operating frequency of $35 \mathrm{~Hz}$. 
TABLE III

BROKEN BAR CONDITION

\begin{tabular}{|c|c|c|c|c|c|}
\hline \multirow[t]{2}{*}{ Source } & \multirow[t]{2}{*}{ Operating Frequency } & \multirow[t]{2}{*}{ Method } & \multicolumn{3}{|c|}{ Condition State } \\
\hline & & & 2 & 3 & 4 \\
\hline \multirow[t]{6}{*}{ AB VSI } & \multirow[t]{2}{*}{$35 \mathrm{~Hz}$} & Nonrobust & $19.05 \%$ & $15.00 \%$ & $13.33 \%$ \\
\hline & & Robust & $45.24 \%$ & $95.00 \%$ & $100.0 \%$ \\
\hline & \multirow[t]{2}{*}{$50 \mathrm{~Hz}$} & Nonrobust & $6.52 \%$ & $92.50 \%$ & $97.83 \%$ \\
\hline & & Robust & $32.61 \%$ & $100.0 \%$ & $100.0 \%$ \\
\hline & \multirow[t]{2}{*}{$65 \mathrm{~Hz}$} & Nonrobust & $73.17 \%$ & $97.96 \%$ & $91.11 \%$ \\
\hline & & Robust & $97.56 \%$ & $100.0 \%$ & $97.78 \%$ \\
\hline \multirow[t]{6}{*}{ Siemens VSI } & \multirow[t]{2}{*}{$35 \mathrm{~Hz}$} & Nonrobust & $9.52 \%$ & $85.71 \%$ & $93.33 \%$ \\
\hline & & Robust & $30.95 \%$ & $100.0 \%$ & $100.0 \%$ \\
\hline & \multirow[t]{2}{*}{$50 \mathrm{~Hz}$} & Nonrobust & $2.33 \%$ & $69.05 \%$ & $71.11 \%$ \\
\hline & & Robust & $23.26 \%$ & $90.48 \%$ & $84.44 \%$ \\
\hline & \multirow[t]{2}{*}{$65 \mathrm{~Hz}$} & Nonrobust & $43.90 \%$ & $45.65 \%$ & $91.11 \%$ \\
\hline & & Robust & $68.29 \%$ & $78.26 \%$ & $95.56 \%$ \\
\hline \multirow[t]{2}{*}{ Utility } & \multirow[t]{2}{*}{$50 \mathrm{~Hz}$} & Nonrobust & $5.00 \%$ & $11.90 \%$ & $2.13 \%$ \\
\hline & & Robust & $35.00 \%$ & $85.71 \%$ & $91.49 \%$ \\
\hline
\end{tabular}

Results of the tests performed with the nonrobust and robust approaches. Percentage of diagnosed tests for each condition state.

Fig 1 shows the tolerance plot with the two chosen fault signatures. The tolerance ellipse obtained with a classical approach only considers as outliers the signatures from 4 tests, while with the robust approach, 12 more tests are marked. This fraction of anomalous data inflates the variance-covariance matrix estimator, affecting the values of the Mahalanobis distances defining classical Hotelling's $T^{2}$ values. The effect of these outliers can be observed in Fig. 2, where the control limits set without removing the outliers are shown (see Fig. 2, top), and when these values have been removed (see Fig. 2, bottom), obtaining a control limit more useful for diagnosis purposes in Phase II.

Fig. 3 shows the control charts in the nonrobust (see Fig. 3, top) and robust versions (see Fig. 3, bottom) when monitoring the IM. The line in the figures corresponds to the quality control warning. If the classical approach were used, some tests belonging to the healthy motor state would be labeled as faulty ones, that is, there would be a warning although the motor is in a healthy state, while the first tests performed with an incipient fault would not be detected. On the contrary, with the robust implementation, these false alarms are eliminated and none of the healthy cases would be mislabeled. Moreover, when the fault is produced, it is almost immediately detected by the control monitoring.

Table III gathers the results of the tests performed with the three voltage sources and three different operating frequencies. The last three columns show the percentage of tests that are diagnosed for each condition state with the nonrobust approaches. It can be observed that the robust approaches always outperformed the nonrobust one. It has to be taken into account that these percentages correspond to the corresponding condition state, but for condition states 3 and 4 , all the cases are diagnosed as faulty, although in some few cases, the degree of severity is not correctly diagnosed.

\section{B. Bearings}

One of the original bearings of a motor of type M1 was replaced by other bearing by SKF. The mounted open-cage ball
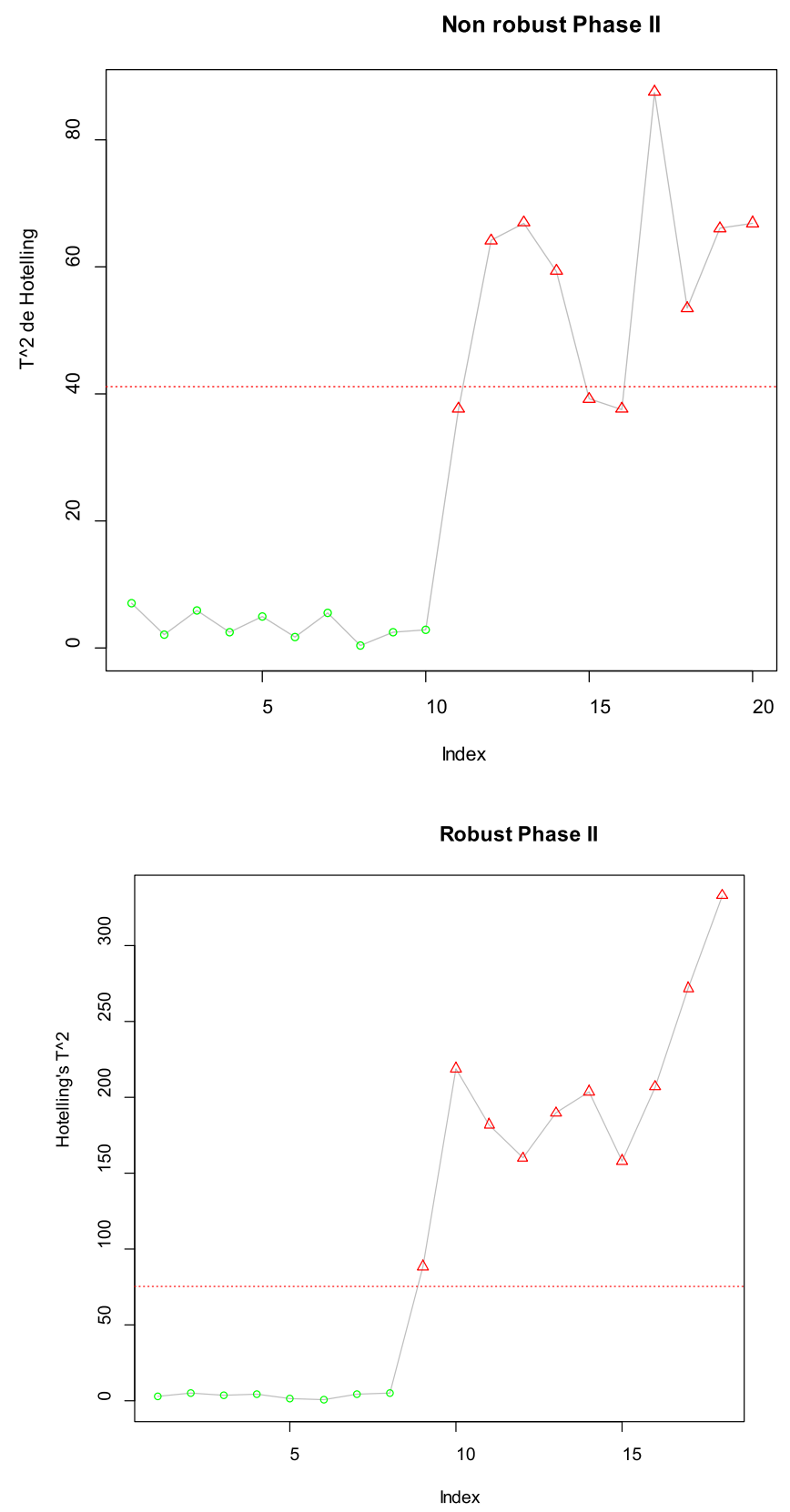

Fig. 4. Phase II charts for bearing faulty state with the motor connected directly to the utility supply and running at full load. Nonrobust (top) and robust (right) approaches. The dots are the healthy motor tests (ten tests). The triangles represent the faulty bearing state (ten tests).

bearing belongs to the 6004 series (characteristic $q$ values were consulted in SKF charts). To provoke the faulty condition, a cut was made in the rolling ring.

As fault signatures, the two first sidebands $[n=1,2$ in (2)] for the fundamental train frequency [52] have been chosen. Figs. 4 and 5 show the control charts when the motor was directly connected to the utility supply. Fig. 4 shows the Phase II control charts in the nonrobust (top) and robust versions (right) when monitoring the IM running at full load. In both cases, there are no false alarms for the healthy state (dots in Fig. 4, ten tests). For the faulty bearing state (ten tests, triangles in 

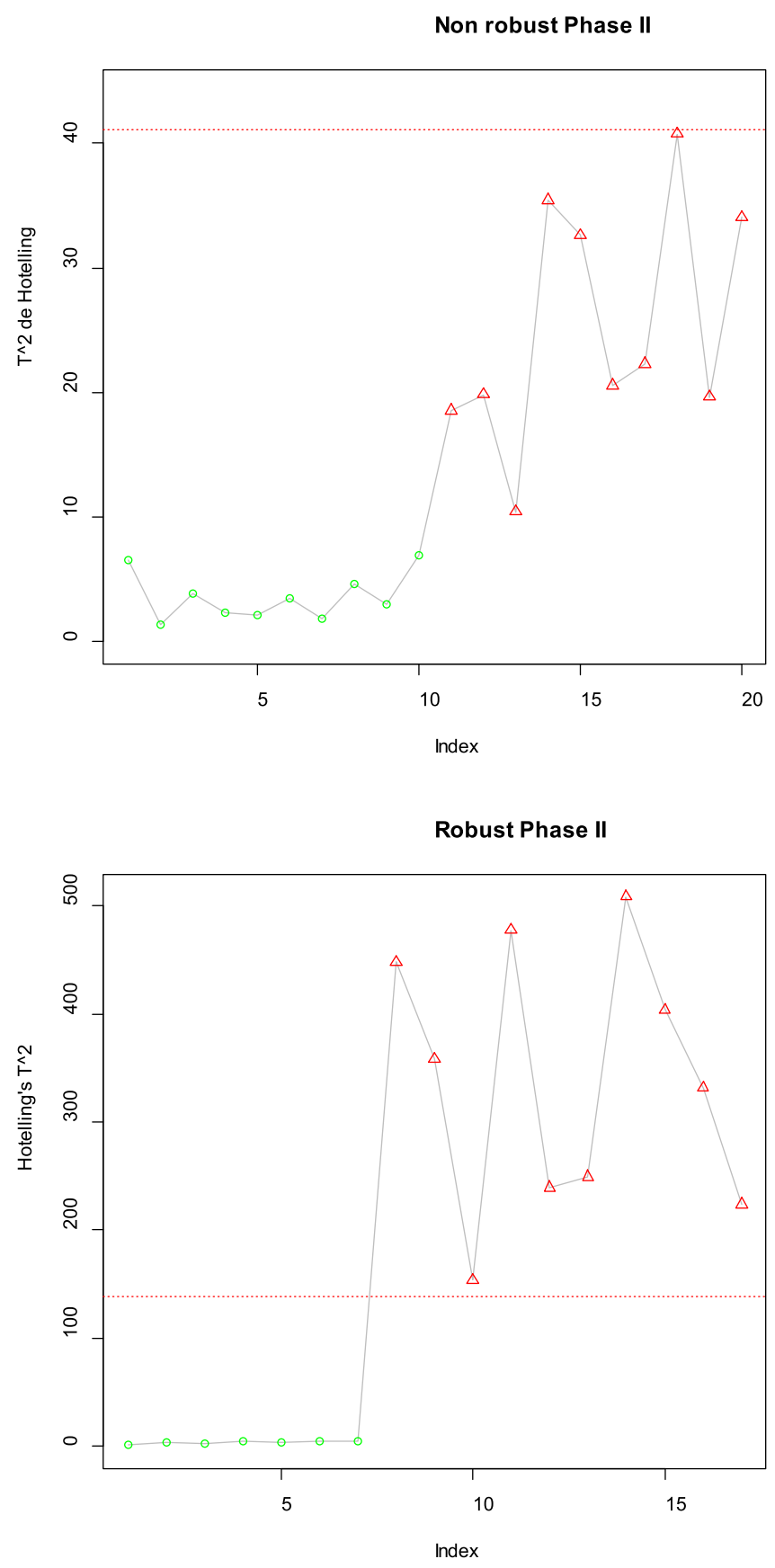

Fig. 5. Phase II charts for bearing faulty state with the motor connected directly to the utility supply and running at almost no load. Nonrobust (top) and robust (right) approaches. The dots are the healthy motor tests (ten tests). The triangles represent the faulty bearing state (ten tests).

Fig. 4), all the tests are detected and diagnosed as faulty with the robust approach, but with the nonrobust one, two of them are mislabeled. In the case shown in Fig. 5, the motor was running at almost no load. In this situation, the nonrobust approach would be completely useless since none of the faulty cases would be detected.

Fig. 6 shows the Phase II control charts in the nonrobust (top) and robust versions (right) when the motor is fed from a VSI by Telemecanique with an assigned frequency of $50 \mathrm{~Hz}$, running at
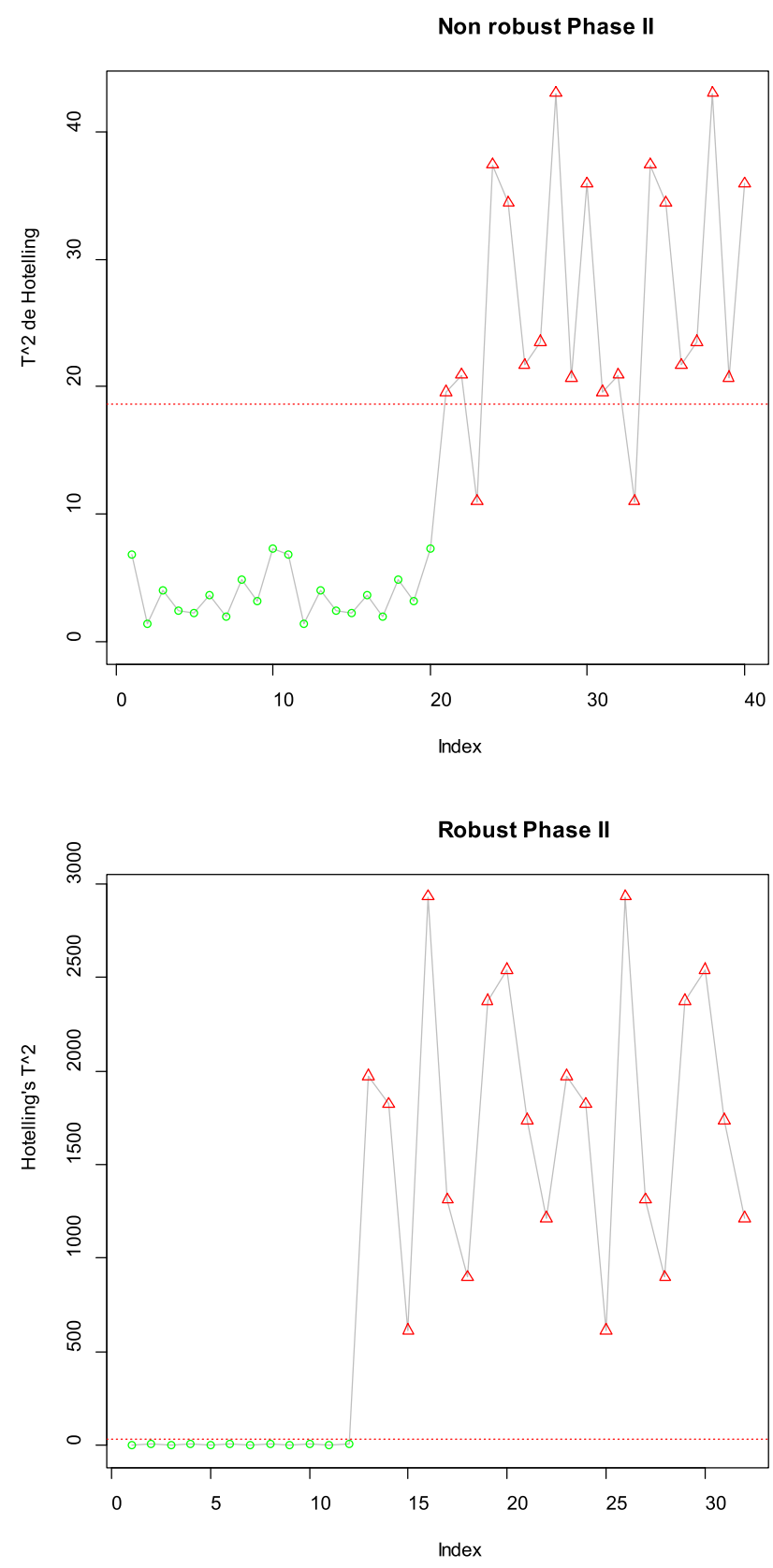

Fig. 6. Phase II charts. Motor fed from a Vart VSI at different loads from almost no load to full load. Nonrobust (top) and robust (right) approaches. The dots are the healthy motor tests (20 tests). The triangles represent the faulty bearing state (20 tests).

different loads from almost no load to full load. In both cases, there are no false alarms for the healthy state (dots, 20 tests). For the faulty bearing state (triangles, 20 tests), all the tests are detected and diagnosed as faulty with the robust approach, but with the nonrobust one, two of them are mislabeled.

\section{Mixed Eccentricity}

An artificially created eccentricity was provoked in a motor of type M2 by putting an L-shaped iron wedge under the motor support held by a pair of cinches. 

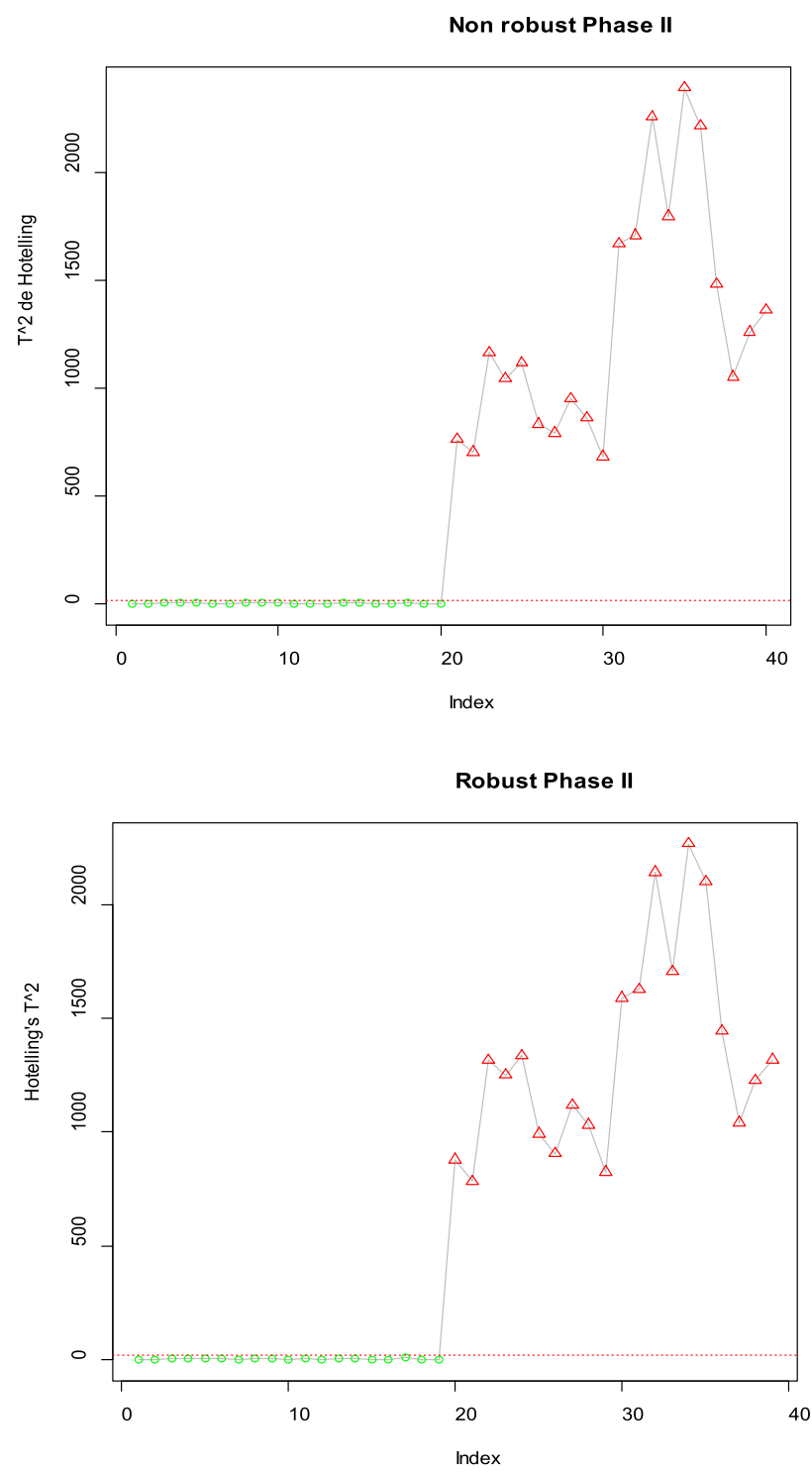

Fig. 7. Phase II chart for the mixed eccentricity case. The motor is fed from a Siemens VSI with an operating frequency of $65 \mathrm{~Hz}$. The dots are the healthy motor tests (20 tests). The triangles represent the mixed eccentricity condition (20 tests)

In the case shown in Fig. 7, the motor was fed from a VSI by Siemens with an assigned frequency of $65 \mathrm{~Hz}$. In this case, there are no false alarms for the healthy state (dots in Fig. 7, 20 tests). For the mixed eccentricity condition (20 tests, triangles in Fig. 7), all the tests are detected and diagnosed as faulty. In this analysis, there is no difference between both approaches.

\section{CONCLUSION}

In this paper, we have developed a procedure for detecting incipient faults in VSI-fed induction motors using multivariate quality control charts and shown its good performance with real motor data under different types of faults. In the case study presented, two motors of different rated power are fed from four different voltage sources, utility supply, and VSIs from three different manufacturers with different assigned frequencies (from 35 to $65 \mathrm{~Hz}$ ) and running at different loads. The main advantage of our technique is that it can be implemented without having observations of the motor in a faulty condition, thus allowing for direct usage in industrial practice with a healthy motor. Another important advantage is that our procedure does not depend on the motor brand or on the feeding system.

The procedure relies on online monitoring using a multiresolution technique based on wavelet functions to detect fault signatures on the spectrum and on a multivariate control chart that incorporates robust statistical procedures for the detection of multivariate outliers corresponding to deteriorated states. This robust technique, which has not been previously considered in the literature for this problem, is aimed at dealing with nonintentional and occasional changes in data, for instance, due to bad measurements or data acquisition problems. This control chart can be implemented using distribution free software, which is the third main advantage of our procedure.

Future work could be focused, as suggested by an anonymous reviewer, on employing techniques from the field of self-adaptive systems, developing models able to adapt and reconfigure as new data are acquired, as well as models from transfer learning, where knowledge acquired while solving a problem can be applied to a related problem.

\section{ACKNOWLEDGMENT}

The authors would like to thank the editor and two anonymous reviewers for their comments, which lead to this improved version of the paper.

\section{REFERENCES}

[1] D. Hyun, J. Hong, S. B. Lee, and K. Kim, "Automated monitoring of airgap eccentricity for inverter-fed induction motors under standstill conditions," IEEE Trans. Ind. Appl., vol. 47, no. 3, pp. 1257-1266, May-Jun. 2011.

[2] B. Akin, U. Orguner, H. A. Toliyat, and M. Rayner, "Low order PWM inverter harmonics contributions to the inverter-fed induction machine fault diagnosis," IEEE Trans. Ind. Electron., vol. 55, no. 2, pp. 610-619, Feb. 2008.

[3] F. Briz, M. W. Degner, P. Garcia, and A. B. Diez, "High-frequency carriersignal voltage selection for stator winding fault diagnosis in inverter-fed ac machines," IEEE Trans. Ind. Electron., vol. 55, no. 12, pp. 4181-4190, Dec. 2008.

[4] O. Duque-Perez, L. A. Garcia-Escudero, D. Morinigo-Sotelo, P. E. Gardel, and M. Perez-Alonso, "Condition monitoring of induction motors fed by Voltage Source Inverters. Statistical analysis of spectral data," in Proc. 2012 XXth Int. Conf. Elect. Mach., Marseille, France, 2012, pp. 24792484.

[5] K. Yahia, A. J. M. Cardoso, S. E. Zouzou, and S. Gueddidi, "Broken rotor bars diagnosis in an induction motor fed from a frequency converter: Experimental research," Int. J. Syst. Assur. Eng. Manag., vol. 3, no. 1, pp. 40-46, Jan.-Mar. 2012.

[6] W. F. Godoy, I. N. da Silva, A. Goedtel, R. H. C. Palácios, and T. D. Lopes, "Application of intelligent tools to detect and classify broken rotor bars in three-phase induction motors fed by an inverter," IET Elect. Power Appl., vol. 10 , no. 5 , pp. 430-439, 2016.

[7] T. Boukra, A. Lebaroud, and G. Clerc, "Statistical and neural-network approaches for the classification of induction machine faults using the ambiguity plane representation," IEEE Trans. Ind. Electron., vol. 60, no. 9, pp. 4034-4042, Sep. 2013.

[8] W. Sun, S. Shao, R. Zhao, R. Yan, X. Zhang, and X. Chen, "A sparse auto-encoder-based deep neural network approach for induction motor faults classification," Measurement, vol. 89, pp. 171-178, Jul. 2016.

[9] E. Cabal-Yepez et al., "FPGA-based entropy neural processor for online detection of multiple combined faults on induction motors," Mech. Syst. Signal Process., vol. 30, pp. 123-130, Jul. 2012 
[10] M. Hernandez-Vargas, E. Cabal-Yepez, and A. Garcia-Perez, "Real-time SVD-based detection of multiple combined faults in induction motors," Comput. Elect. Eng., vol. 40, no. 7, pp. 2193-2203, Oct. 2014.

[11] P. Gardel, D. Morinigo-Sotelo, O. Duque-Perez, M. Perez-Alonso, and L. A. Garcia-Escudero, "Neural network broken bar detection using time domain and current spectrum data," in Proc. 2012 XXth Int. Conf. Elect. Mach., Marseille, France, 2012, pp. 2492-2497.

[12] M. Seera and C. P. Lim, "Online motor fault detection and diagnosis using a hybrid FMM-CART model," IEEE Trans. Neural Netw. Learn. Syst., vol. 25, no. 4, pp. 806-812, Apr. 2014.

[13] V. N. Ghate and S. V. Dudul, "Cascade neural-network-based fault classifier for three-phase induction motor," IEEE Trans. Ind. Electron., vol. 58, no. 5, pp. 1555-1563, May 2011.

[14] V. N. Ghate and S. V. Dudul, "Optimal MLP neural network classifier for fault detection of three phase induction motor," Expert Syst. Appl., vol. 37, no. 4, pp. 3468-3481, Apr. 2010.

[15] H. L. Schmitt, L. R. B. Silva, P. R. Scalassara, and A. Goedtel, "Bearing fault detection using relative entropy of wavelet components and artificial neural networks," in Proc. 2013 9th IEEE Int. Symp. Diagn. Electric Mach., Power Electron. Drives, Valencia, Spain, 2013, pp. 538-543.

[16] M. D. Prieto, G. Cirrincione, A. G. Espinosa, J. A. Ortega, and H. Henao, "Bearing fault detection by a novel condition-monitoring scheme based on statistical-time features and neural networks," IEEE Trans. Ind. Electron., vol. 60, no. 8, pp. 3398-3407, Aug. 2013.

[17] H. C. Cho, J. Knowles, M. S. Fadali, and K. S. Lee, "Fault detection and isolation of induction motors using recurrent neural networks and dynamic Bayesian modeling," IEEE Trans. Control Syst. Technol., vol. 18, no. 2, pp. 430-437, Mar. 2010.

[18] B. Liang, S. D. Iwnicki, and Y. Zhao, "Application of power spectrum, cepstrum, higher order spectrum and neural network analyses for induction motor fault diagnosis," Mech. Syst. Signal Process., vol. 39, no. 1-2, pp. 342-360, Aug.-Sep. 2013.

[19] P. K. Kankar, S. C. Sharma, and S. P. Harsha, "Fault diagnosis of ball bearings using machine learning methods," Expert Syst. Appl., vol. 38, no. 3, pp. 1876-1886, Mar. 2011.

[20] J. Zarei, "Induction motors bearing fault detection using pattern recognition techniques," Expert Syst. Appl., vol. 39, no. 1, pp. 68-73, Jan. 2012.

[21] F. Jia, Y. Lei, J. Lin, X. Zhou, and N. Lu, "Deep neural networks: A promising tool for fault characteristic mining and intelligent diagnosis of rotating machinery with massive data," Mech. Syst. Signal Process., vol. 72-73, pp. 303-315, May 2016.

[22] S. Hamdani, H. Mezerreg, B. Boutikar, N. Lahcene, O. Touhami and R. Ibtiouen, "Rotor fault diagnosis in a squirrel-cage induction machine using support vector machine," in Proc. 2012 XXth Int. Conf. Elect. Mach., Marseille, France, 2012, pp. 1817-1822.

[23] Y. K. Moorthy, P. S. Chandran, and S. Rishidas, "Motor current signature analysis by multi-resolution methods using support vector machine," in Proc. 2011 IEEE Recent Adv. Intell. Comput. Syst., Trivandrum, India, 2011, pp. 096-101.

[24] D. Matić, F. Kulić, M. Pineda-Sánchez, and I. Kamenko, "Support vector machine classifier for diagnosis in electrical machines: Application to broken bar," Expert Syst. Appl., vol. 39, no. 10, pp. 299-312, Aug. 2012.

[25] H. Keskes, A. Braham, and Z. Lachiri, "Broken rotor bar diagnosis in induction machines through stationary wavelet packet transform and multiclass wavelet SVM,' Electric Power Syst. Res., vol. 97, pp. 151-157, Apr. 2013.

[26] H. O. Vishwakarma, K. S. Sajan, B. Maheshwari, and Y. D. Dhiman, "Intelligent bearing fault monitoring system using support vector machine and wavelet packet decomposition for induction motors," in Proc. 2015 Int. Conf. Power Adv. Control Eng., Bangalore, India, 2015, pp. 339-343.

[27] J. Zarei, M. M. Arefi, and H. Hassani, "Bearing fault detection based on interval type-2 fuzzy logic systems for support vector machines," in Proc. 2015 6th Int. Conf. Modeling, Simulation, Appl. Optim., Istanbul, Turkey, 2015, pp. 1-6.

[28] P. Konar and P. Chattopadhyay, "Bearing fault detection of induction motor using wavelet and support vector machines (SVMs)," Appl. Soft Comput., vol. 11, no. 6, pp. 4203-4211, Sep. 2011.

[29] S. B. Salem, K. Bacha, and A. Chaari, "Support vector machine based decision for mechanical fault condition monitoring in induction motor using an advanced Hilbert-Park transform," ISA Trans., vol. 51, no. 5, pp. 566-572, Sep. 2012.

[30] C. Rajeswari, B. Sathiyabhama, S. Devendiran, and K. Manivannan, "Bearing fault diagnosis using wavelet packet transform, hybrid PSO and support vector machine," Procedia Eng., vol. 97, pp. 1772-1783, 2014.
[31] X. Zhang and J. Zhou, "Multi-fault diagnosis for rolling element bearings based on ensemble empirical mode decomposition and optimized support vector machines," Mech. Syst. Signal Process., vol. 41, no. 1-2, pp. 127140, Dec. 2013.

[32] K. Zhu, X. Song, and D. Xue, "A roller bearing fault diagnosis method based on hierarchical entropy and support vector machine with particle swarm optimization algorithm," Measurement, vol. 47, pp. 669-675, Jan. 2014.

[33] C. Delpha, H. Chen, and D. Diallo, "SVM based diagnosis of inverter fed induction machine drive: A new challenge," in Proc. 38th Annu. Conf. IEEE Ind. Electron. Soc., Montreal, QC, Canada, 2012, pp. 3931-3936.

[34] A. Bouguerne, A. Lebaroud, A. Medoued, and A. Boukadoum, "Classification of induction machine faults by K-nearest neighbor," in Proc. 2011 7th Int. Conf. Elect. Electron. Eng., Bursa, Turkey, 2011, pp. I-363-I-366.

[35] M. Farajzadeh-Zanjani, R. Razavi-Far, M. Saif, J. Zarei, and V. Palade, "Diagnosis of bearing defects in induction motors by fuzzy-neighborhood density-based clustering," in Proc. 2015 IEEE 14th Int. Conf. Mach. Learn. Appl., Miami, FL, USA, 2015, pp. 935-940.

[36] H. W. Peng and P. J. Chiang, "Control of mechatronics systems: Ball bearing fault diagnosis using machine learning techniques," in Proc. 2011 8th Asian Control Conf., Kaohsiung, Taiwan, 2011, pp. 175-180.

[37] S. P. Santos and J. A. F. Costa, "A comparison between hybrid and nonhybrid classifiers in diagnosis of induction motor faults," in Proc. 11th IEEE Int. Conf. Comput. Sci. Eng. 2008, Sao Paulo, 2008, pp. 301-306.

[38] S. Ergin, S. Tezel, and M. B. Gulmezoglu, "DWT-based fault diagnosis in induction motors by using CVA," in Proc. 2011 Int. Symp. Innov. Intell. Syst. Appl., Istanbul, Turkey, 2011, pp. 129-132.

[39] G. Georgoulas et al., "Principal component analysis of the start-up transient and hidden Markov modeling for broken rotor bar fault diagnosis in asynchronous machines," Expert Syst. Appl., vol. 40, no. 17, pp. 70247033, Dec. 2013.

[40] A. Soualhi, G. Clerc, H. Razik, and A. Lebaroud, "Fault detection and diagnosis of induction motors based on hidden Markov model," in Proc. 2012 XXth Int. Conf. Elect. Mach., Marseille, France, 2012, pp. 16931699.

[41] S. Yusuf, D. J. Brown, A. Mackinnon, and R. Papanicolaou, "Fault classification improvement in industrial condition monitoring via hidden Markov models and Näve Bayesian modeling," in Proc. 2013 IEEE Symp. Ind. Electron. Appl., Kuching, 2013, pp. 75-80.

[42] V. Sugumaran and K. I. Ramachandran, "Automatic rule learning using decision tree for fuzzy classifier in fault diagnosis of roller bearing," Mech. Syst. Signal Process., vol. 21, no. 5, pp. 2237-2247, Jul. 2007.

[43] M. Seera, C. P. Lim, S. Nahavandi, and C. K. Loo, "Condition monitoring of induction motors: A review and an application of an ensemble of hybrid intelligent model," Expert Syst. Appl., vol. 41, no. 10, pp. 4891-4903, Aug. 2014.

[44] C. T. Yiakopoulos, K. C. Gryllias, and I. A. Antoniadis, "Rolling element bearing fault detection in industrial environments based on a K-means clustering approach," Expert Syst. Appl., vol. 38, no. 3, pp. 2888-2911, Mar. 2011.

[45] X. Jin, F. Yuan, T. W. S. Chow, and M. Zhao, "Weighted local and global regressive mapping: A new manifold learning method for machine fault classification," Eng. Appl. Artif. Intell., vol. 30, pp. 118-128, Apr. 2014.

[46] A. Bellini, F. Filippetti, C. Tassoni, and G. A. Capolino, "Advances in diagnostic techniques for induction machines," IEEE Trans. Ind. Electron., vol. 55 no. 12, pp. 4109-4126, Dec. 2008.

[47] J.M.F. Fonseca, B.M. Sousa, W.E. Aguiar, A.R. Braga, A.P. Lemos, and H.C.C. Michel, "Monitoring of a thermoelectric power plant based on multivariate statistical process control," in Proc. 2016 IEEE Conf. Evolving Adaptive Intell. Syst., pp. 49-56.

[48] F. Filippetti, A. Bellini, and G. A. Capolino, "Condition monitoring and diagnosis of rotor faults in induction machines: State of art and future perspectives," in Proc. 2013 IEEE Workshop Elect. Mach. Design Control Diagn., Paris, France, 2013, pp. 196-209.

[49] O. Duque-Perez, L. A. Garcia-Escudero, D. Morinigo-Sotelo, P. E. Gardel, and M. Perez-Alonso, "Analysis of fault signatures for the diagnosis of induction motors fed by voltage source inverters using ANOVA and additive models," Elect. Power Syst. Res., vol. 121, pp. 1-13, 2015.

[50] M. Fernandez-Temprano, P. E. Gardel-Sotomayor, O. Duque-Perez, and D. Morinigo-Sotelo, "Broken bar condition monitoring of an induction motor under different supplies using a linear discriminant analysis," in Proc. 2013 9th IEEE Int. Symp. Diagn. Elect. Mach., Power Electron. Drives, pp. 162-168. 
[51] M. E. H. Benbouzid and G. B. Kliman, "What stator current processingbased technique to use for induction motor rotor faults diagnosis?" IEEE Trans. Energy Convers., vol. 18, no. 2, pp. 238-244, Jun. 2003.

[52] O. Duque, M. Perez, and D. Morinigo, "Detection of bearing faults in cage induction motors fed by frequency converter using spectral analysis of line current," in Proc. IEEE Int. Conf. Elect. Mach. Drives, San Antonio, TX, USA, 2005, pp. 17-22.

[53] D. C. Montgomery, Introduction to Statistical Quality Control, 7th ed., New York, NY, USA: Wiley, 2012.

[54] G. Hanrahan, Environmental Chemometrics: Principles and Modern Applications. CRC Press, Boca Ratón, FL, USA, 2008.

[55] E. B. Howington, "Robust monitoring of contaminated multivariate data," Adv. Decision Sci., vol. 2013, Art. ID 961501, 5 pages, 2013, doi: $10.1155 / 2013 / 961501$.

[56] R. L. Mason and J. C. Young, Multivariate Statistical Process Control with Industrial Applications. ASA/SIAM, Philadelphia, PA, USA, 2002.

[57] R. L. Mason, N. D. Tracy, and J. C. Young, "Decomposition of $\mathrm{T}^{2}$ for multivariate control chart interpretation," J. Qual. Technol., vol. 27, pp. 109-119, 1995.

[58] D. M. Hawkings, "Multivariate quality control based on regressionadjusted variables," Technometrics, vol. 33, pp. 61-75, 1993

[59] N. Das and V. Prakash, "Interpreting the out-of-control signal in multivariate control chart-A comparative study," Int. J. Adv. Manuf. Technol., vol. 37, pp. 966-979, 2008

[60] S. Vidal-Puig and A. Ferre, "A comparative study of different methodologies for fault diagnosis in multivariate quality control," Commun. Stat. Simul. Comput., vol. 43, pp. 986-1005, 2014.

[61] E. Alfaro, J. L. Alfaro, M. Gámez, and N. García, "A comparison of different classification techniques to determine the change causes in Hotelling's T2 control chart," in Proc. Qual. Reliab. Eng. Int., 2015, vol. 31, pp. 1255-1263.

[62] R. E. Schapire and Y. Freund, Boosting: Foundations and Algorithms. MIT Press, Hoboken, NJ, USA, 2012.

[63] P. J. Rousseeuw and A. M. Leroy, Robust Regressions and Outlier Detection, New York, NY, USA: Wiley, 1987.

[64] W. A. Jensen, J. B. Birch, and W. H. Woodall, "High breakdown estimation for phase I multivariate control charts," Quality Reliab. Eng. Int., vol. 23, pp. 615-629, 2007.

[65] J. L. Alfaro and J. F. Ortega, "A robust alternative to Hotelling's T2 control chart using trimmed estimators," Qual. Reliab. Eng. Int., vol. 24, pp. 601-611, 2008

[66] G. Stefatos and A. B. Hamza, "Fault detection using robust multivariate control chart," Expert Syst. Appl., vol. 36, pp. 5888-5894, 2009.

[67] G. Pison, S. Van Aelst, and G. Willems, "Small sample corrections for LTS and MCD," Metrika, vol. 55, pp. 111-123, 2002.

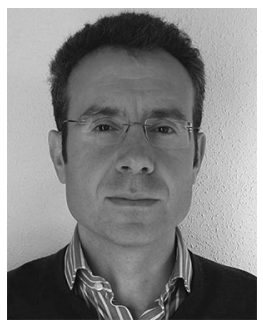

Valladolid (IMUVA).

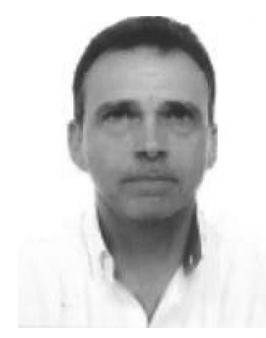

Oscar Duque-Perez received the B.S. and Ph.D. degrees in electrical engineering from the University of Valladolid (UVA), Valladolid, Spain, in 1992 and 2000 , respectively.

In 1994, he joined the E.T.S. de Ingenieros Industriales, UVA, where he is currently Full Professor with the Research Group in Predictive Maintenance and Testing of Electrical Machines, Department of Electrical Engineering. His current research interests include power systems reliability, condition monitoring, and heuristic optimization techniques.

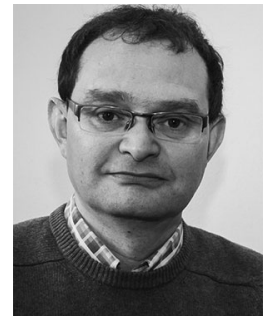

Miguel Fernandez-Temprano received the B.S. degree in mathematics, in 1991, and the Ph.D. degree in statistical science, in 1995 from the Universidad de Valladolid, Valladolid, Spain.

He is currently Professor Titular de Universidad in the Department of Statistics and Operational Research of the Universidad de Valladolid. His current research interests include statistical analysis of motor faults, statistical inference methods under restrictions, circular data, computational biology, and reliability and maintenance of complex systems.

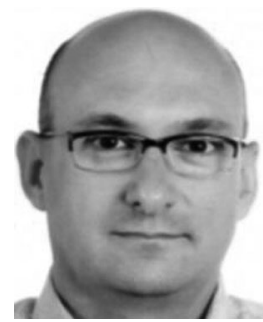

Daniel Morinigo-Sotelo (M'04) received the B.S. and $\mathrm{Ph} . \mathrm{D}$. degrees in electrical engineering from the University of Valladolid (UVA), Valladolid, Spain, in 1999 and 2006, respectively.

He was a Research Collaborator on Electromagnetic Processing of Materials with the Light Alloys Division of CIDAUT Foundation from 2000 until 2015. He is currently with the Research Group in Predictive Maintenance and Testing of Electrical Machines, Department of Electrical Engineering, UVA, and with the HSPdigital Research Group, México. His current research interests include condition monitoring of induction machines, optimal electromagnetic design, and heuristic optimization.
Luis Angel García-Escudero received the B.S. and Ph.D. degrees in mathematics from the Universidad of Valladolid (UVA), Valladolid, Spain, in 1993 and 1996, respectively.

Since 1998, he has been a Professor Titular de Universidad in the Department of Statistics and Operational Research, UVA. His current research interests include robust statistics, unsupervised classification techniques, monitoring techniques, and reliability analysis. He is also a Member of the Instituto de Investigación en Matemáticas de la Universidad de 